EGU21-8269, updated on 18 May 2021

https://doi.org/10.5194/egusphere-egu21-8269

EGU General Assembly 2021

(c) Author(s) 2021. This work is distributed under

the Creative Commons Attribution 4.0 License.

\title{
Virtual outcrops: Field work on lockdown conditions using Drones
}

\author{
Fernando Borrás ${ }^{1}$, Joaquín Hopfenblatt ${ }^{2}$, Adelina Geyer ${ }^{2}$, and Meritxell Aulinas ${ }^{3}$ \\ ${ }^{1}$ Drones for Geology, Barcelona, Spain (fernando@drones4geology.com) \\ ${ }^{2}$ Geosciences Barcelona, GEO3BCN - CSIC, Barcelona, Spain (joaquinhopfenblatt@gmail.com; ageyer@geo3bcn.csic.es) \\ ${ }^{3}$ Departament de Mineralogia, Petrologia i Geologia Aplicada, University of Barcelona, Marti Franques s/n, 08028, \\ Barcelona, Spain (meritxellaulinas@ub.edu)
}

The year 2020 was full of challenges in many aspects, and it was not an exception for Earth Science education. Field work, which is the most effective tool for developing the capacity of spatial visualization of Geology students, was restricted, or even banned, during long time periods. The lockdown conditions highlighted the immediate need of techniques that "could" bring the field to our classrooms and homes through electronic devices.

The use of "Remotely Piloted Aircraft System" (RPAS), commonly known as drones, for geological purposes is increasing year after year involving different fields of geology, such as hazard assessment, monitoring, volcanology, structural geology among others. Drones allow obtaining, for an affordable price (compared to airplane or helicopter renting) and under safe conditions, updated aerial photography from any perspective resulting in a more efficient fieldwork. At present, there are different working teams using drones mainly for geological research purposes. However, those focused on teaching innovation systems by combining science and drone technology are still limited.

We propose the use of this technology to create 3D virtual outcrops with research or teaching purposes. Indeed, in those cases in which face-to-face teaching is not possible or the outcrop is located in a hard-to-reach or hazardous areas, virtual fieldtrips can be a valuable and safe alternative. Moreover, it approaches geological outcrops to people with physical disability or with reduced mobility promoting a more inclusive environment. Virtual outcrops also offer scientist, students and the general public the opportunity to visit, explore and study remote places all over the world with the possibility of creating a worldwide virtual catalog of outcrops with importance in Earth Sciences. Among other interesting applications there is the possibility of combining drone generated products with geographic information systems (GIS), photogrammetry and virtual modelling software's, widely used by research institutions and universities which would open a full new scope of studies for students and professors.

Since the second half of year 2020, "Drones4Geology" cooperative, in collaboration with universities and research centers, is building a collection of high-quality 3D virtual outcrops and orthomosaics obtained from drone photogrammetry of different sites of Catalonia considered of geological interest, (e.g., Southern Pyrenean fold and thrust belt, Hercynian intrusive rocks of la 
"Costa Brava") aiming to put these 2D and 3D tools at the disposal of students and researchers. 